\title{
Growth factor-induced release of placental alkaline phosphatase from human syncytiotrophoblast membranes
}

\author{
P. Kenton and P. M. Johnson \\ Department of Immunology, University of Liverpool, Liverpool L69 3BX, UK
}

\begin{abstract}
The ability of epidermal growth factor, insulin or guanosine thiotriphosphate to induce the release of two glycosyl-phosphatidylinositol-linked proteins from isolated human placental syncytiotrophoblast plasma membrane vesicles was investigated. Epidermal growth factor induced the ATP-dependent release of a fraction of syncytiotrophoblast plasma membrane placental alkaline phosphatase, whereas no release was detected following insulin treatment. This effect of epidermal growth factor was apparent at $30 \mathrm{~min}$ but not at $5 \mathrm{~min}$. Guanosine thiotriphosphate stimulated the release of a small amount of syncytiotrophoblast plasma membrane placental alkaline phosphatase and appeared to have an additive effect when applied together with epidermal growth factor. Guanosine thiodiphosphate did not induce phosphatase release, but partially inhibited the epidermal growth factor response. $28.7 \%$ of syncytiotrophoblast plasma membrane 5 '-nucleotidase was solubilized using glycosylphosphatidylinositol-specific phospholipase C. However, unlike placental alkaline phosphatase, no detectable release of $5^{\prime}$-nucleotidase was observed following treatment of syncytiotrophoblast plasma membrane vesicles with epidermal growth factor or guanosine thiotriphosphate. These results indicate (i) the presence of at least two placental alkaline phosphatase-releasing pathways in syncytiotrophoblast plasma membrane vesicles, and (ii) the presence of subpopulations of glycosyl-phosphatidylinositol-linked proteins sensitive to growth factor-induced release.
\end{abstract}

\section{Introduction}

Placental alkaline phosphatase is a $130 \mathrm{kDa}$ dimeric sialoglycoprotein expressed on the cell surface of human placental syncytiotrophoblast as well as certain tumours, notably of the reproductive tract (McLaughlin et al., 1983; McDicken et al., 1985). Placental alkaline phosphatase, like several other cellsurface proteins, is anchored to the plasma membrane by a glycosyl-phosphatidylinositol (GPI) linkage, a structure sensitive to cleavage by phosphatidylinositol-specific phospholipase C (PI-PLC) (Low and Saltiel, 1988; Webb and Todd, 1988). Placental alkaline phosphatase is released, by an unknown mechanism, into the serum of pregnant women and patients with tumours expressing placental alkaline phosphatase (Vergote et al., 1992). The significance of release of placental alkaline phosphatase for the progress of either gestation or cancer is unknown. It has been suggested recently that it can function as an IgG-Fc receptor (Makiya and Stigbrand, 1992). It is possible that liberated placental alkaline phosphatase can bind to a cell surface inositol receptor via its inositol-glycan moiety (as has been demonstrated for hepatocyte heparan sulfate proteoglycan) and is subsequently internalized together with bound IgG (Ishihara et al., 1987).

A potential mechanism for the release of placental alkaline phosphatase is suggested by the liberation of GPI-linked

Received 17 February 1993. proteins from the cell surface following treatment of cells with insulin (Chan et al., 1988; Romero et al., 1988; Lisanti et al., 1989; Romero, 1991). In experiments in which the human laryngeal carcinoma cell line, HEp-2, was treated with epidermal growth factor (EGF), insulin or a non-hydrolysable analogue of guanosine triphosphate, guanosine thiotriphosphate (GTP $\gamma \mathrm{S}$, a GTP analogue that can persistently activate GTPbinding proteins), a small but reproducible release of placental alkaline phosphatase was induced by each agent (Neer and Clapham, 1988; Roberts et al., 1990). Thus, growth factor activation of tumour cells, utilizing a mechanism that may involve a guanosine triphosphate (GTP)-binding protein, could be responsible for the appearance of placental alkaline phosphatase in the serum of cancer patients.

Isolated syncytiotrophoblast plasma membrane vesicles were shown to express receptors for EGF and insulin together with components of several signalling pathways, such as adenylyl cyclase, phospholipase $\mathrm{C}$, and $\mathrm{G}$ proteins (Figgs, 1988; Roberts et al., 1991; Jacobs et al., 1992; Johnson, 1992). Some of these components were shown to be coupled to functioning signalling pathways in these membranes (Carpenter et al., 1980; Webb and Mahadevan, 1987; Figgs, 1988; Kenton et al., 1989, 1991). To determine whether growth factor stimulation of syncytiotrophoblast induces release of placental alkaline phosphatase, we treated syncytiotrophoblast plasma membrane vesicles with EGF, insulin or guanine nucleotide analogues and measured the release of placental 
alkaline phosphatase and another GPI-linked protein, 5 '-nucleotidase (CD73) expressed on the extracellular surface of cells (Vogel et al., 1992). This enzyme has been identified on plasma membranes prepared from placental homogenates (Thompson et al., 1987; Klemens et al., 1990).

\section{Materials and Methods}

\section{Materials}

Clostridium perfringens phosphatidylcholine-specific phospholipase C (PC-PLC; EC 3.1.4.3), human placental alkaline phosphatase (EC 3.1.3.1), murine EGF, bovine insulin, adenosine, adenosine monophosphate, ATP, GTP $\gamma$, GDP $\beta$, $p$-nitrophenylphosphate ( $\mathrm{pNPP}$; as 'phosphate substrate' tablets), $\beta$-glycerol phosphate, $\mathrm{Ba}(\mathrm{OH})_{2}, \mathrm{ZnSO}_{4}$, pepstatin $\mathrm{A}$, bromelain and phenylmethylsulfonyl fluoride (PMSF) were obtained from Sigma (Poole, Dorset). Bacillus cereus PI-PLC (EC 3.1.4.10) and E64 (N-[N-(L-3-trans-carboxyoxiran-2-carbonyl)L-leucyll-agmatine) were obtained from Boehringer-Mannheim (Lewes). [ $\left.{ }^{3} \mathrm{H}\right] 5^{\prime} \mathrm{AMP}$ ( $>30 \mathrm{Ci} \mathrm{mmol}{ }^{-1}$ ) was obtained from New England Nuclear (through Du Pont (UK) Ltd, Stevenage). Triton X-100 was obtained from BDH (Liverpool).

\section{Preparation of syncytiotrophoblast plasma membrane vesicles}

Syncytiotrophoblast plasma membrane vesicles were isolated from human term villous placental tissue within $\mathrm{I} \mathrm{h}$ of delivery as described by Webb and Mahadevan (1987).

\section{Placental alkaline phosphatase release assay}

Specific conditions for each placental alkaline phosphatase release assay are given with the appropriate figure. Incubations (except those using bromelain) were carried out in the presence of the protease inhibitors PMSF $\left(0.2 \mathrm{mmol} \mathrm{l^{-1 }}\right)$, pepstatin A $\left(1 \mu \mathrm{mol} \mathrm{l} \mathrm{I}^{-1}\right)$ and E64 ( $\left.1.4 \mu \mathrm{mol} \mathrm{I} \mathrm{I}^{-1}\right)$. Since tyrosine kinase activity may be essential for any effect of EGF or insulin, incubations using these growth factors were carried out in the presence or absence of ATP. Divalent cations were also added, as most phosphorylation that occurs in syncytiotrophoblast plasma membrane vesicles requires the presence of these ions (Kenton et al., 1989). After incubation, the membranes were centrifuged at $11000 \mathrm{~g}$ for $10 \mathrm{~min}$ (in an MSE Micro-Centaur) and an aliquot of the supernatant was gently decanted and dispensed into a fresh tube. This supernatant was centrifuged again (10 min at $11000 \mathrm{~g}$ ) and an aliquot gently removed and dispensed into a fresh tube. This supernatant, $50 \mu \mathrm{l}$, was then assayed for placental alkaline phosphatase or $5^{\prime}$-nucleotidase, as detailed below. Alternatively, membrane suspensions of syncytiotrophoblast plasma membrane vesicles were centrifuged at $133000 \mathrm{~g}$ for $30 \mathrm{~min}$ in a Beckman airfuge and the supernatants assayed for placental alkaline phosphatase activity.

\section{Placental alkaline phosphatase and $5^{\prime}$-nucleotidase assays}

Typically, placental alkaline phosphatase was measured by its ability to use pNPP (dissolved in $100 \mathrm{mmol}$ ethanolamine
$\mathrm{l}^{-1}\left(\mathrm{pH} \mathrm{9.4)}\right.$ containing $5 \mathrm{mmol} \mathrm{MgCl}_{2} \mathrm{I}^{-1}$ ) as a substrate at room temperature, generating a yellow solution absorbing light at $405 \mathrm{~nm}$. Placental alkaline phosphatase was also measured by a specific enzymeimmunoassay using the murine IgGI monoclonal antibody, H317 (a gift of P. J. McLaughlin, Department of Immunology, University of Liverpool), as previously described (McLaughlin et al., 1983, 1984a, b). H317 specifically recognizes placental alkaline phosphatase but not germ cell placental-type alkaline phosphatase. Assays were standardized using purified human placental alkaline phosphatase of known enzymatic activity per mg protein. Absorbance was measured using a Titertek Multiscan Plus.

5 -Nucleotidase was measured using the method of Stanley et al. (1980). Briefly, a sample of syncytiotrophoblast plasma membrane vesicle supernatant (typically $50 \mu \mathrm{l}$ ) was incubated with $450 \mu \mathrm{l}$ of a solution containing $50 \mathrm{mmol}$ Tris- $\mathrm{HCl} \mathrm{l}^{-1}$ ( $\mathrm{pH} 7.4$ ), $0.1 \%$ Triton $X-100,2 \mathrm{mmol} \mathrm{MgCl}_{2} \mathrm{I}^{-1}, 20 \mathrm{mmol}$ $\beta$-glycerol phosphate $\mathrm{I}^{-1}, 0.268 \mathrm{mg}$ adenosine $\mathrm{ml}^{-1}$, $0.2 \mathrm{mmol} 5^{\prime}$-AMP $1^{-1}$ and $0.45 \mu \mathrm{Ci}(15 \mathrm{pmol})\left[^{3} \mathrm{H}\right] 5^{\prime}$-AMP. Incubation was carried out at $37^{\circ} \mathrm{C}$ for $15 \mathrm{~min}$ and the reaction terminated by addition of $300 \mu \mathrm{l} 150 \mathrm{mmol} \mathrm{ZnSO}_{4} \mathrm{I}^{-1}$ followed by $200 \mu \mathrm{l}$ of $0.3 \mathrm{~mol} \mathrm{Ba}(\mathrm{OH})_{2} 1^{-1}$. After centrifugation for $1 \mathrm{~min}$ at $11000 \mathrm{~g}$, aliquots of the terminated reaction supernatant were counted in Optiphase Hisafe 3 (LKB) using an LKB 1216 RackBeta liquid scintillation counter.

\section{Results}

Syncytiotrophoblast plasma membrane vesicles were incubated with increasing concentrations of either EGF or insulin to determine whether these growth factors induce the release of placental alkaline phosphatase. EGF or insulin alone, or insulin with ATP, showed no effect on placental alkaline phosphatase release (Figs 1 and 2). EGF with ATP, however, induced a small but reproducible increase in the release of placental alkaline phosphatase.

Some reports have suggested that, following insulin treatment of whole cells, GPI-linked proteins are released into the medium rapidly (within $5 \mathrm{~min}$ ) with extracellular concentrations returning to near basal values by $30 \mathrm{~min}$ (Chan $\mathrm{et}$ al., 1988). Syncytiotrophoblast plasma membrane vesicles were incubated with EGF or insulin (in the presence of ATP) for 5 and $30 \mathrm{~min}$ to test whether this is also the case for syncytiotrophoblast membrane preparations. No effect on release of placental alkaline phosphatase was seen with EGF at 5 min or with insulin at 5 or $30 \mathrm{~min}$ (Table 1). After incubation with EGF for $30 \mathrm{~min}$, however, a significant increase in release of placental alkaline phosphatase was seen.

Syncytiotrophoblast plasma membrane vesicles were incubated with increasing concentrations of either GTP $\gamma \mathrm{S}$ or guanosine thiodiphosphate (GDP $\beta S$ ) to test whether a GTPbinding protein is involved in the release of placental alkaline phosphatase. GTP $\gamma S$ induced the release of a small proportion of the placental alkaline phosphatase of syncytiotrophoblast plasma membrane vesicles, whereas GDP $\beta S$ (which inactivates GTP-binding proteins) did not affect the amount of placental alkaline phosphatase in syncytiotrophoblast plasma membrane vesicles supernatants (Fig. 3). 


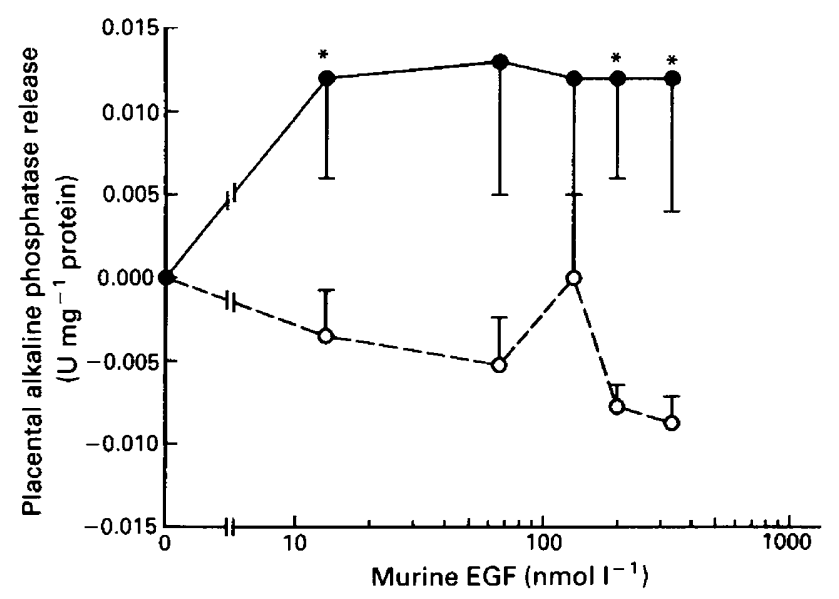

Fig. 1. Effects of epidermal growth factor (EGF) on activity of placental alkaline phosphatase in syncytiotrophoblast plasma membrane vesicles. $384 \mu \mathrm{g}$ syncytiotrophoblast plasma membrane vesicle protein was incubated for $30 \mathrm{~min}$ at $37^{\circ} \mathrm{C}$ with EGF, (O) with or (O) without $0.1 \mathrm{mmol}$ ATP $\mathrm{l}^{-1}$, in $10 \mathrm{mmol}$ Tris- $\mathrm{HCl} 1^{-1}(\mathrm{pH} \mathrm{7.4})$ containing protease inhibitors. The incubation buffer contained $1.0 \mathrm{mmol} \mathrm{MnCl} \mathrm{M}^{-1}, 1.0 \mathrm{mmol} \mathrm{CaCl}_{2} \mathrm{l}^{-1}$ and $1.0 \mathrm{mmol} \mathrm{MgCl}_{2} \mathrm{l}^{-1}$. The total volume was $100 \mu \mathrm{l}$. Supernatants were assayed for placental alkaline phosphatase activity $(n=4)$. Data are shown with buffer control value subtracted. Vertical bars represent standard errors. ${ }^{*} P<0.05$ tested by Mann-Whitney test (EGF plus ATP versus EGF alone).

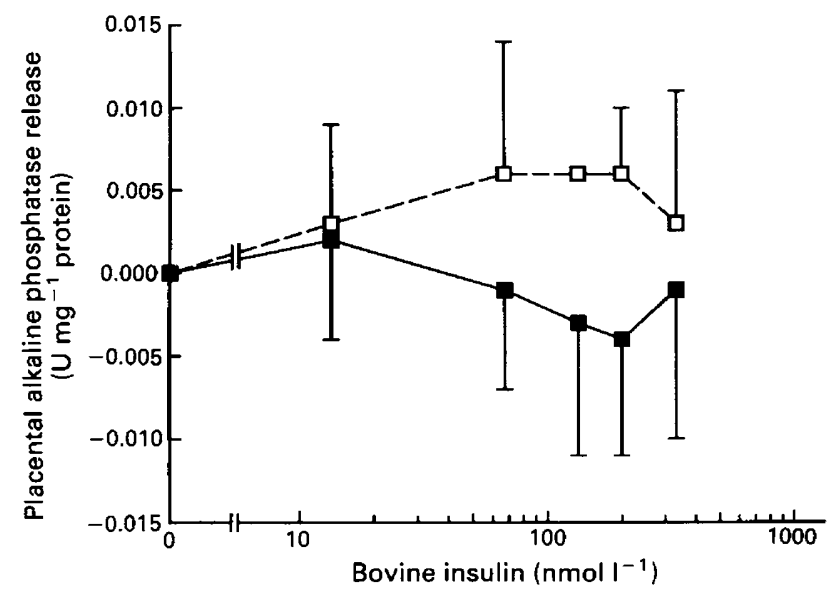

Fig. 2. Effects of insulin on activity of alkaline phosphatase of syncytiotrophoblast plasma membrane vesicles. $384 \mu \mathrm{g}$ syncytiotrophoblast plasma membrane vesicle protein was incubated for $30 \mathrm{~min}$ at $37^{\circ} \mathrm{C}$ with insulin, $(\square)$ with or $(\square)$ without 0.1 mmol ATP $l^{-1}$, in 10 mmol Tris- $\mathrm{HCl} \mathrm{l}^{-1}(\mathrm{pH} \mathrm{7.4)} \mathrm{containing} \mathrm{protease} \mathrm{inhibitors.} \mathrm{The}$ incubation buffer contained $1.0 \mathrm{mmol} \mathrm{l^{-1 }}$ of $\mathrm{MnCl}_{2}, \mathrm{CaCl}_{2}$ and $\mathrm{MgCl}_{2}$. The total volume was $100 \mu \mathrm{l}$. Supernatants were assayed for placental alkaline phosphatase activity $(n=4)$. Data are shown with buffer control value subtracted. Vertical bars represent standard errors.

Syncytiotrophoblast plasma membrane vesicles were incubated with either GTP $\gamma S$ or GDP $\beta$, in the presence of EGF and ATP, to determine whether EGF and GTP-binding proteins interact in the release of placental alkaline phosphatase. GTP $\gamma S$ enhanced the EGF-induced release of placental alkaline phosphatase but, compared with earlier results (Figs $I$ and 2), the effect was additive rather than synergistic (Table 2). GDPßS, however, partially inhibited the EGF-induced release of placental alkaline phosphatase. The possibility that any effect of insulin on release of this enzyme might be GTP dependent was tested, but insulin failed to stimulate any measurable increase in soluble placental alkaline phosphatase in the presence of GTP $\gamma S\left(17.2 \pm 16.4 \mathrm{mU} \mathrm{mg}^{-1}\right.$ syncytiotrophoblast plasma membrane vesicle protein, $P=0.37, n=4$ ).

The results obtained with EGF/ATP or GTP $\gamma S$ were shown not to be due to contamination by microvesicles and the released alkaline phosphatase activity was shown to be placental alkaline phosphatase by incubating syncytiotrophoblast plasma membrane vesicles with EGF and ATP or GTP $\gamma \mathrm{S}$. The membranes were removed by ultracentrifugation and the placental alkaline phosphatase activity in the resulting supernatant was assessed by enzymeimmunoassay (Table 3). EGF with ATP induced a small but significant release of the enzyme. GTP $\gamma S$ also induced significant release of placental alkaline phosphatase. The precise amounts of placental alkaline phosphatase released in these experiments were different from those obtained in earlier experiments. However, quantitative data obtained in the enzymeimmunoassay are not necessarily comparable with those obtained from the enzyme assay. The enzymeimmunoassay for placental alkaline phosphatase is approximately threefold less sensitive than the enzyme assay and is more variable, having an intra-assay coefficient of variation of $5.82 \%$, compared with $1.79 \%$ for the enzyme assay.

Although $5^{\prime}$-nucleotidase is GPI-linked to whole placental membranes, the extent to which this enzyme is GPI-anchored to syncytiotrophoblast plasma membrane vesicles is unknown (Thompson et al., 1987; Klemens et al., 1990). The mean $5^{\prime}$-nucleotidase activity detected in syncytiotrophoblast plasma membrane vesicles was $76.6 \pm 2.3 \mathrm{U} 5^{\prime}$-nucleotidase $\mathrm{mg}^{-1}$ protein (data not shown). Treatment of syncytiotrophoblast plasma membrane vesicles with PI-PLC (from Bacillus cereus) gave a dose-dependent increase in the release of $5^{\prime}$-nucleotidase up to $1 \mathrm{mU}$ PI-PLC $\mathrm{ml}^{-1}$. Maximum release with PI-PLC accounted for $28.7 \%$ of total $5^{\prime}$-nucleotidase in the vesicles. Phosphatidylcholine-specific phospholipase C (from Clostridium perfringens) had no effect on $5^{\prime}$-nucleotidase release (Table 4).

Treatment of syncytiotrophoblast plasma membrane vesicles with EGF or insulin, in the presence or absence of ATP, did not result in the release of a significant amount of $5^{\prime}$-nucleotidase. Similarly, treatment with GTP $\gamma S$ gave no detectable rise in soluble $5^{\prime}$-nucleotidase activity (Table 4).

Treatment of syncytiotrophoblast plasma membrane vesicles with EGF or insulin, in the presence or absence of ATP, did not result in the release of a significant amount of $5^{\prime}$-nucleotidase. Similarly, treatment with GTP $\gamma \mathrm{S}$ gave no detectable rise in soluble 5 '-nucleotidase activity (Table 4).

\section{Discussion}

Insulin induces the release of GPI-linked proteins from the surface of cells (Chan $e t$ al., 1988; Romero et al., 1988; Lisanti et al., 1989; Romero, 1991). EGF and GTP $\gamma S$ influence the release of a GPI-anchored protein, placental alkaline phosphatase, from the human laryngeal carcinoma cell-line, HEp-2 (Roberts et al., 
Table 1. Effect of short incubation with epidermal growth factor (EGF) or insulin on release of placental alkaline phosphatase from human syncytiotrophoblast plasma membrane vesicles

\begin{tabular}{lccc}
\hline & & Placental alkaline phosphatase release $^{\mathbf{a}}$ & \\
\cline { 3 - 3 } Treatment & Time $(\mathrm{min})$ & $\left(\mathrm{mU} \mathrm{mg}^{-1}\right.$ SPMV protein) & $P$ \\
\hline Buffer alone & & $77.0 \pm 3.0$ & n.s. \\
EGF & 5 & $79.3 \pm 3.0$ & $<0.05$ \\
EGF & 30 & $97.6 \pm 3.0$ & n.s. \\
Insulin & 5 & $74.6 \pm 2.9$ & n.s. \\
Insulin & 30 & $84.1 \pm 1.4$ & \\
\hline
\end{tabular}

Values are means $\pm \operatorname{SEM}(n=5)$.

${ }^{\mathrm{a}} 417 \mu \mathrm{g}$ syncytiotrophoblast plasma membrane vesicle protein was incubated at $37^{\circ} \mathrm{C}$ with either EGF $\left(300 \mathrm{nmol} \mathrm{l}{ }^{-1}\right)$ or insulin $\left(300 \mathrm{nmol} \mathrm{l}^{-1}\right)$, with $\left.0.1 \mathrm{mmol} \mathrm{ATP}\right]^{-1}$, in $10 \mathrm{mmol}$ Tris- $\mathrm{HCl} \mathrm{I}^{-1}(\mathrm{pH} \mathrm{7.4)} \mathrm{containing} \mathrm{protease} \mathrm{inhibitors} \mathrm{for} \mathrm{various} \mathrm{times.} \mathrm{Total}$ volume was $100 \mu \mathrm{l}$. The incubation buffer contained $1.0 \mathrm{mmol} \mathrm{l}^{-1}$ of $\mathrm{MnCl}_{2}, \mathrm{CaCl}_{2}$ and $\mathrm{MgCl}_{2}$. Supernatants were assayed for placental alkaline phosphatase activity. Significance of differences between treatment groups and the buffer control assessed by Student's $t$ test.

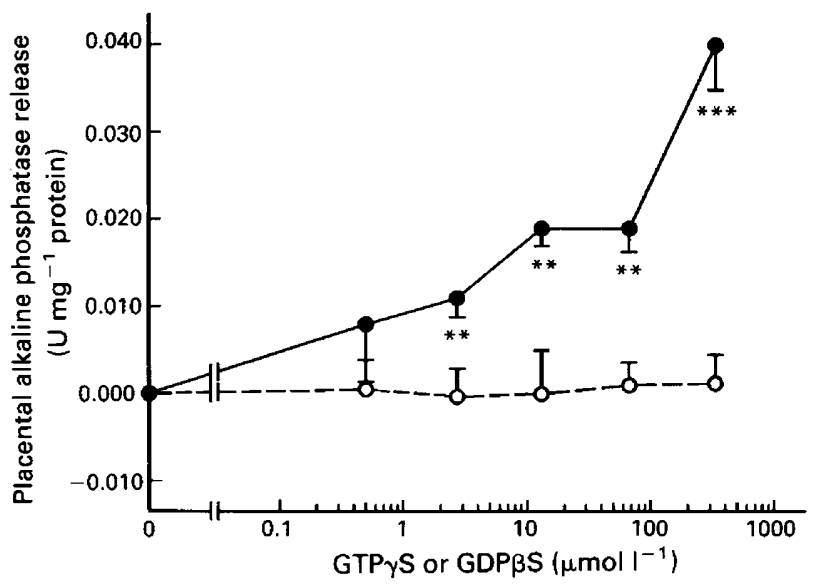

Fig. 3. Effects of guanosine thiotriphosphate $(\mathrm{GTP} \gamma \mathrm{S})$ and guanosine thiodiphosphate (GDP $\beta S$ ) on placental alkaline phosphatase activity in syncytiotrophoblast plasma membrane vesicles. $312 \mu \mathrm{g}$ syncytiotrophoblast plasma membrane vesicle protein was incubated for $30 \mathrm{~min}$ at $37^{\circ} \mathrm{C}$ with either guanosine thiotriphosphate (GTPyS) (O) or guanosine thiodiphosphate (GDP $\beta S$ ) $(O)$ in $10 \mathrm{mmol}$ Tris- $\mathrm{HCl} 1^{-1}$ ( $\mathrm{pH} 7.4$ ) containing protease inhibitors. The total volume was $100 \mu \mathrm{I}$. Supernatants were assayed for placental alkaline phosphatase activity $(n=6)$. Data are shown with buffer control value subtracted. Vertical bars represent standard errors. ${ }^{* *} P<0.01,{ }^{* * *} P<0.001$ assessed by Student's $t$ test (GTP $\gamma S$ versus GDP $\beta S$ ).

1990). We have now extended these studies to determine whether similar events occur at the plasma membrane of a normal human cell, placental syncytiotrophoblast. Placental alkaline phosphatase is expressed not only on this cell surface, but also by many solid tumours (McLaughlin et al., 1983; McDicken et al., 1985). This alkaline phosphatase is released into the circulation during pregnancy and in the course of malignancy (Vergote et al., 1992). The physiological significance and the full mechanism of this release remain unresolved. Growth factor-induced release of placental alkaline phosphatase may be a candidate for such a mechanism.

EGF induces the release of a small, but significant proportion of the placental alkaline phosphatase of syncytiotrophoblast
Table 2. Effects of epidermal growth factor (EGF) and guanosine thiotriphosphate (GTP $\gamma$ S) or guanosine thiodiphosphate (GDP $\beta S$ ) on placental alkaline phosphatase activity in human syncytiotrophoblast plasma membrane vesicles

\begin{tabular}{lcc}
\hline & \multicolumn{2}{c}{ Placental alkaline phosphatase release $^{\mathrm{a}}$} \\
\cline { 2 - 2 } Treatment & $\left(\mathrm{mU} \mathrm{mg}^{-1}\right.$ protein $)$ & $p$ \\
\hline Buffer alone & $58.67 \pm 2.28$ & \\
EGF + buffer & $64.83 \pm 3.20$ & $<0.01$ \\
EGF + GTP $\gamma S$ & $69.59 \pm 3.20$ & $<0.001$ \\
EGF + GDP $\beta S$ & $59.89 \pm 2.28$ & n.s. \\
\hline
\end{tabular}

Values are means $\pm \operatorname{SEM}(n=9)$.

${ }^{\mathrm{a}} 312 \mu \mathrm{g}$ syncytiotrophoblast plasma membrane vesicle protein was incubated for $30 \mathrm{~min}$ at $37^{\circ} \mathrm{C}$ with EGF $\left(300 \mathrm{nmol} \mathrm{l} \mathrm{l}^{-1}\right)$ and ATP $\left(0.1 \mathrm{mmol} \mathrm{l} \mathrm{l}^{-1}\right)$ and either GTP $\gamma S\left(300 \mu \mathrm{mol} \mathrm{l^{-1 }}\right)$ or GDP $\beta S\left(300 \mu \mathrm{mol} \mathrm{I} \mathrm{I}^{-1}\right)$ in $10 \mathrm{mmol}$ Tris- $\mathrm{HCl} 1^{-1}(\mathrm{pH} 7.4)$ containing protease inhibitors. The total volume was $100 \mu \mathrm{l}$. The incubation buffer contained $1.0 \mathrm{mmol} \mathrm{I}^{-1}$ of $\mathrm{MnCl}_{2}, \mathrm{CaCl}_{2}$ and $\mathrm{MgCl}_{2}$. Supernatants were assayed for placental alkaline phosphatase activity. Significance of differences between treatment groups and buffer control was assessed by Wilcoxon one-sample rank test.

plasma membrane vesicles. The ability of EGF to affect this release depends on the presence of ATP, which suggests that phosphorylation may play a role. Although it has been reported that insulin stimulates the release of GPI-linked proteins, no evidence for such release was seen in syncytiotrophoblast plasma membrane vesicles in the presence or absence of ATP. However, maximal insulin-stimulated release of this alkaline phosphatase in HEp-2 cells amounted to only half of that released following EGF treatment and, therefore, it is possible that the assay conditions were insufficiently sensitive to measure an insulin effect in syncytiotrophoblast plasma membrane vesicles (Roberts et al., 1990). The proportion of total cell-surface placental alkaline phosphatase released by EGF $(0.4 \%)$ was comparable to (and not significantly different from) that stimulated by EGF in HEp-2 cells (1.6\%), suggesting that the low value for release is not an artefact of the membrane system used (Roberts et al., 1990). Chan et al. (1988) observed that treatment of cells with insulin resulted in the 
Table 3. Effects of epidermal growth factor (EGF) and guanosine thiotriphosphate (GTP $\gamma$ S) treatment on placental alkaline phosphatase activity in human syncytiotrophoblast plasma membrane vesicles

\begin{tabular}{|c|c|c|}
\hline & Placental alkaline phosphatase release & \\
\hline Treatment & $\left(\mathrm{mU} \mathrm{mg}^{-1}\right.$ protein $^{\mathbf{a}}$ & $P$ \\
\hline Buffer alone & $36.21 \pm 1.42$ & - \\
\hline $\begin{array}{l}\text { EGF and ATP } \\
(n=12)\end{array}$ & $38.53 \pm 1.26$ & $<0.01$ \\
\hline Buffer alone & $49.61 \pm 2.43$ & - \\
\hline $\begin{array}{l}\text { GTP } \gamma S \\
(n=11)\end{array}$ & $54.40 \pm 1.99$ & $<0.05$ \\
\hline
\end{tabular}

Values are means \pm SEM

${ }^{a} 360 \mu \mathrm{g}$ syncytiotrophoblast plasma membrane vesicle protein was incubated for $30 \mathrm{~min}$ at $37^{\circ} \mathrm{C}$ with either EGF $\left(300 \mathrm{nmol}^{-1}\right)$ and $0.1 \mathrm{mmol} \mathrm{ATP} \mathrm{I}^{-1}$ or GTP $\gamma \mathrm{S}\left(300 \mu \mathrm{mol} \mathrm{I}^{-1}\right)$ in $10 \mathrm{mmol}$ Tris- $\mathrm{HCl} \mathrm{I}^{-1}$ ( $\mathrm{pH} \mathrm{7.4)} \mathrm{containing} \mathrm{protease}$ inhibitors. The total volume was $100 \mu$ l. For experiments with EGF and ATP, the incubation buffer contained $1 \mathrm{mmol} 1^{-1}$ of $\mathrm{MnCl}_{2}, \mathrm{CaCl}_{2}$ and $\mathrm{MgCl}_{2}$. After incubation, the syncytiotrophoblast plasma membrane vesicle suspension was centrifuged at $133000 \mathrm{~g}$ for $30 \mathrm{~min}$ and the supernatants were assayed for placental alkaline phosphatase activity by enzyme immunoassays. Significance of differences between treatment groups and buffer control was assessed by Wilcoxon one-sample rank test.

Table 4. Effects of epidermal growth factor (EGF), insulin and guanine nucleotides on $5^{\prime}$-nucleotidase of syncytiotrophoblast plasma membrane vesicles

\begin{tabular}{lcc}
\hline & & $5^{\prime}$-Nucleotidase release \\
\cline { 3 - 3 } Treatment & Number of samples & $\left(\mathrm{mU} \mathrm{mg} \mathrm{I}^{-1} \text { protein }\right)^{\mathrm{a}}$ \\
\hline PLPLC & 3 & $21.42 \pm 0.64$ \\
PC-PLC & 3 & $-0.18 \pm 0.07$ \\
EGF/ATP & 4 & $0.020 \pm 0.008$ \\
EGF & 4 & $-0.024 \pm 0.018$ \\
Insulin/ATP & 4 & $-0.007 \pm 0.013$ \\
Insulin & 4 & $-0.012 \pm 0.023$ \\
GTPYS & 4 & $-0.396 \pm 0.090$ \\
GDP $\beta S$ & 4 & $-0.716 \pm 0.110$ \\
\hline
\end{tabular}

Values are means \pm SEM.

${ }_{1}^{\mathrm{a}} 125 \mu \mathrm{g}$ syncytiotrophoblast plasma membrane vesicle protein was incubated for $30 \mathrm{~min}$ at $37^{\circ} \mathrm{C}$ with either $1 \mathrm{mU}$ PI-PLC $\mathrm{ml}^{-1}, 1 \mathrm{mU}$ PC-PLC $\mathrm{ml}^{-1}$

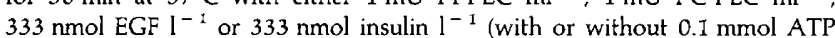
$\mathrm{I}^{-1}$ ), or with $333 \mu \mathrm{mol}$ GTP $\gamma S \mathrm{I}^{-1}$ or $333 \mu \mathrm{mol}$ GDPßS $\mathrm{I}^{-1}$ in $10 \mathrm{mmol}$ Tris $-\mathrm{HCl} \mathrm{I}^{-1}(\mathrm{pH} \mathrm{7.4)}$ containing protease inhibitors. For incubations containing EGF or insulin the buffer also contained $1.0 \mathrm{mmol} \mathrm{I}^{-1}$ of $\mathrm{MnCl}_{2}, \mathrm{CaCl}_{2}$ and $\mathrm{MgCl}_{2}$. The total volume was $100 \mu$ l. Data are shown with buffer control value subtracted. Supernatants were assayed for 5 '-nucleotidase activity.

PI-PLC: phosphatidyl-inositol-specific phospholipase $C_{i}$ PC-PLC: phosphatidylcholine-specific phospholipase C; GTP $\gamma \mathrm{S}$ : guanosine thiotriphosphate; GDP $\beta S$ : guanosine thiodiphosphate.

liberation of soluble alkaline phosphatase with maximal release at $2 \mathrm{~min}$, followed by the return of alkaline phosphatase in the extracellular medium to basal values by $30 \mathrm{~min}$. This effect was considered to be due to either degradation of the released enzyme or internalization. In syncytiotrophoblast plasma membrane vesicles, however, no effect of EGF was noted on placental alkaline phosphatase at $5 \mathrm{~min}$, but a significant increase in soluble placental alkaline phosphatase was observed at $30 \mathrm{~min}$. This indicates that (i) EGF-stimulated release of placental alkaline phosphatase from syncytiotrophoblast plasma membrane vesicles is substantially slower than insulininduced phosphatase release in $\mathrm{BC}_{3} \mathrm{HI}$ myocytes, and (ii) the degradation/internalization mechanism is absent from, or inactive in, trophoblast membrane preparations.

GTP $\gamma \mathrm{S}$ stimulated the release of a small subpopulation of placental alkaline phosphatase from syncytiotrophoblast plasma membrane vesicles compared with the nonhydrolysable guanosine diphosphate analogue, GDPßS. GTP $\gamma S$ has been shown to stimulate $G$ proteins, whereas GDP $\beta S$ inhibits G proteins (Neer and Clapham, 1988). This finding suggests the presence of a GTP-binding protein coupled to the mechanism for placental alkaline phosphatase release. GTP $\gamma S$ stimulated the release of approximately $0.77 \%$ of total enzyme. This is lower than the values for EGF action on syncytiotrophoblast plasma membrane vesicles or for GTP $\gamma \mathrm{S}$ action on HEp-2 cells (4.3\%).

The effect on release of placental alkaline phosphatase of treatment of vesicles with EGF and GTP $\gamma$ S in combination was additive, signifying that the EGF effect on release of this enzyme does not involve a GTP-binding protein, as a GTPbinding-protein-coupled receptor would be expected to exhibit either synergism or uncoupling when treated with both agonist and GTP analogue. Furthermore, this finding indicates that the EGF-induced mechanism operates on a subset of cell surface placental alkaline phosphatase separate from that used by the GTP $\gamma$ S-dependent mechanism. The observation that GDP $\beta S$ partially inhibited EGF-stimulated placental alkaline phosphatase release suggests that, although the EGF receptor may not be coupled to placental alkaline phosphatase release by a GTP-binding protein, it is sensitive to downstream modulation involving one or more GTP-binding proteins.

It is possible that the alkaline phosphatase released in these studies resulted from EGF- or GTP $\gamma$ S-induced microvesiculation. This mechanism appears to be excluded by the observation that placental alkaline phosphatase is still enriched in ultracentrifugation supernatants from EGF/ATP- or GTP $\gamma S$ treated syncytiotrophoblast plasma membrane vesicles. Furthermore, since EGF/ATP and GTP $\gamma S$ lead to the release of the alkaline phosphatase, but not of $5^{\prime}$-nucleotidase, it would appear that fragmentation of the membranes cannot explain release of placental alkaline phosphatase. The same set of experiments also demonstrated that the alkaline phosphatase activity released is recognized by the $\mathrm{H} 317$ monoclonal antibody specific for placental alkaline phosphatase (McLaughlin et al., 1983, 1984a, b).

Another GPI-linked protein of the placenta, 5 '-nucleotidase, was also studied to determine whether GPI-linked proteins are differentially regulated by growth factors or GTP-binding proteins, as has been suggested by Lisanti et al. (1989). $5^{\prime}$-nucleotidase is known to be coupled to the cell surface by a GPI-anchor in several cells (reviewed by Lisanti et al., 1990). A proportion of $5^{\prime}$-nucleotidase from syncytiotrophoblast plasma membrane vesicles was shown to be sensitive to PI-PLC. This finding provides supportive evidence that this protein is GPI-linked to the cell surface of human trophoblast. However, over $60 \%$ of $-5^{\prime}$-nucleotidase of syncytiotrophoblast plasma 
membrane vesicles was resistant to PI-PLC. This finding contrasts with a previous study in which over $80 \%$ of 5 '-nucleotidase associated with membranes prepared from whole placental homogenates was sensitive to PI-PLC (Thompson et al., 1987). 5'-Nucleotidase was shown to be more resistant than was alkaline phosphatase to release by PI-PLC (reviewed by Turner et al., 1991).

Neither EGF nor insulin treatment resulted in a significant release of $5^{\prime}$-nucleotidase, irrespective of whether ATP was included in the incubation. Similarly, GTP $\gamma S$ was ineffective. This result supports the contention that subsets of GPI-linked proteins are sensitive to growth factor-induced release, whereas other GPI-anchored proteins are resistant.

In conclusion, these studies showed that small but discrete populations of placental alkaline phosphatase of syncytiotrophoblast plasma membrane vesicles were sensitive to growth factor-induced release and to release by a mechanism that involves GTP-binding proteins. Another GPI-linked protein, $5^{\prime}$-nucleotidase, was resistant to such release. Thus, it seems that different GPI-linked proteins and different populations of the same GPI-anchored protein are partitioned into groups with varying degrees of sensitivity to extracellular signals.

The authors acknowledge the generous project grant support of the Wigan and District Cancer Research Committee. They also wish to thank J. M. Roberts and P. D. Webb for their helpful discussions.

\section{References}

Carpenter G, Poisner L and King L (1980) Protein phosphorylation in human placenta: stimulation by epidermal growth factor Molecular and Cellular Endocrinology 18 189-199

Chan BL, Lisanti MP, Rodriguez-Boulan E and Saltiel AR (1988) Insulinstimulated release of lipoprotein lipase by metabolism of its phosphatidylinositol anchor Science 241 1670-1672

Figgs LW (1988) Guanine nucleotide binding in human placental syncytiotrophoblast membranes and comparative regulation of adenylate cyclase in syncytiotrophoblast, turkey erythrocytes and bovine calf testes membranes by guanosine- $5^{\prime}$-triphosphate Comparative Biochemistry and Physiology 89B $119-125$

Ishihara M, Fedarko NS and Conran HE (1987) Involvement of phosphatidylinositol and insulin in the co-ordinate regulation of proteo-heparan sulfate metabolism and hepatocyte growth Journal of Biological Chemistry 262 4708-4716

Jacobs MM, Li X and Illsley NP (1992) Dual regulation of human syncytial adenylyl cyclase Placenta 13 123-133

Johnson PM (1992) Immunobiology of human extraembryonic fetal membranes. In Immunological Obstetrics pp 177-188 Eds CB Coulam, WP Faulk and JA McIntyre. WW Norton and Co., New York

Kenton P, Johnson PM and Webb PD (1989) The phosphorylation of p68, a calcium-binding protein associated with the human syncytiotrophoblast submembraneous cytoskeleton, is modulated by growth factors, activators of protein kinase C and cyclic AMP Biochimica et Biophysica Acta 1014 271-281

Kenton P, Webb PD, Lister RK and Johnson PM (1991) Does human syncytiotrophoblast express the M-CSF receptor/c-fms protein product? In Uterine and Embryonic Factors in Early Pregnancy pp 141-204 Eds JR Strausse III and CR Lyttle. Plenum Press, New York

Klemens MR, Sherman WR, Holmsberg NJ, Ruedi JM, Low MG and Thompson LF (1990) Characterization of soluble vs membrane-bound human placental

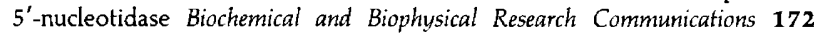
1371-1377
Lisanti MP, Darnell JC, Chan BL, Rodriguez-Boulan E and Saltiel AR (1989) The distribution of glycosyl-phosphatidylinositol anchored proteins is differentially regulated by serum and insulin Biochemical and Biophysical Research Communications 164 824-832

Lisanti MP, Rodriguez-Boulan E and Saltiel AR (1990) Emerging functional roles for the glycosyl-phosphatidylinositol membrane protein anchor Journal of Membrane Biology 117 1-10

Low MG and Saltiel AR (1988) Structural and functional roles of glycosylphosphatidylinositol in membranes Science 239 268-275

McDicken IW, McLaughlin PJ, Tromans PM, Luesley DM and Johnson PM (1985) Detection of placental-type alkaline phosphatase in ovarian cancer British Journal of Cancer 52 59-64

McLaughlin PJ, Gee HO and Johnson PM (1983) Placental-type alkaline phosphatase in pregnancy and malignant plasma - specific estimation using a monoclonal antibody in a solid-phase enzyme-immunoassay Clinica Chimica Acta 130 199-209

McLaughlin PJ, Travers PJ, McDicken IW and Johnson PM (1984a) Demonstration of placental and placental-like alkaline phosphatase in non-malignant tissues using monoclonal antibodies in an enzyme immunoassay Clinica Chimica Acta 137 341-348

McLaughlin PJ, Twist AM, Evans CC and Johnson PM (1984b) Serum placentaltype alkaline phosphatase in cigarette smokers Journal of Clinical Pathology $37826-828$

Makiya R, Stigbrand T (1992) Placental alkaline phosphatase is related to human $\operatorname{lgG}$ internalisation in HEp2 cells Biochemical and Biophysical Research Communications 182 624-630

Neer EJ and Clapham DE (1988) Roles of G protein subunits in transmembrane signalling Nature 333 129-134

Roberts JM, Kenton P and Johnson PM (1990) Growth factor-induced release of a glycosyl-phosphatidylinositol (GPI)-linked protein from the HEp-2 human carcinoma cell line FEBS Letters $267213-216$

Roberts JM, Kenton P and Johnson PM (1991) Growth factor-induced release of a glycosyl-phosphatidylinositol (GPI)-linked protein from the HEp-2 human carcinoma cells and human syncytiotrophoblast Biochemical Society Transactions $19106 \mathrm{~S}$

Romero G (1991) Inositolglycans and cellular signalling Cell Biology International Reports 15 827-852

Romero G, Luttrell L, Rogol A, Zeller K, Hewlett E and Larner J (1988) Phosphatidylinositol-glycan anchors of membrane proteins: precursors of insulin mediators Science $240509-511$

Stanley KK, Edwards MR and Luzio JP (1980) Subcellular distribution and movement of $5^{\prime}$-nucleotidase in rat cells Biochemical Joumal 186 59-69

Thompson LF, Ruedi JM and Low MG (1987) Purification of $5^{\prime}$-nucleotidase from human placenta after release from plasma membranes by phosphatidylinositol-specific phospholipase C Biochemical and Biophysical Research Communications 145 118-125

Turner AJ, dos Santos-Medeiros M and Hooper NM (1991) The molecular biology of GPI-anchored border hydrolases Cell Biology International Reports 15 1083-1099

Vergote IB, Abeler VM, Bormer OP, Stigbrand T, Trope C and Nustad K (1992) CA125 and placental alkaline phosphatase as serum markers in epithelial ovarian carcinoma Tumour Biology 13 168-174

Vogel M, Kowalewski H, Zimmermann H, Hooper NM and Turner AJ (1992) Soluble low-Km 5'-nucleotidase from electric ray (Torpedo marmorata) electric organ and bovine cerebral cortex is derived from the glycosylphosphatidylinositol-anchored ectoenzyme by phospholipase C cleavage Biochemical Journal 284 621-624

Webb PD and Mahadevan LC (1987) Calcium-dependent binding proteins associated with human placental syncytiotrophoblast microvillous cytoskeleton Biochimica et Biophysica Acta 916 288-297

Webb PD and Todd J (1988) Attachment of human placental-type alkaline phosphatase via phosphatidylinositol to syncytiotrophoblast and tumour cell plasma membranes European Journal of Biochemistry 172 647-652 